\title{
INTERJECTIONS IN SCANDINAVIA AND BEYOND: TRADITIONS AND INNOVATIONS
}

\author{
Eva Skafte Jensen, \\ Dansk Sprognævn \\ esj@dsn.dk \\ Tina Thode Hougaard, \\ Aarhus University \\ nortth@cc.au.dk \\ Carsten Levisen, \\ Roskilde University \\ calev@ruc.dk
}

As a research area, the study of interjections is characteristic in that it is very heterogeneously treated. In grammars it is sometimes mentioned as a lexical category, sometimes it is completely neglected. In pragmatic studies, it is sometimes considered the most fundamental part of communication, sometimes it is almost not observed at all. The Danish tradition is no different. With a few exceptions, in most grammars and handbooks on Danish, the subject is hardly mentioned at all. This may be due to the fact that interjections from a grammatical point of view may seem less than interesting. With the point of departure in the criteria typically used in the work resulting in lexical categories, there is not much to be said, morpho-syntactically speaking. In fact, as pointed out in most of the papers of this volume, the real interesting features of interjecions lie in their communicative functions. Nevertheless, in many studies on interjections the traditional morpho-syntactic approach to linguistic items may reveal itself indirectly. As point in case, the idea of talking of primary and secondary interjections stems from such an approach. In grammatical studies, it is quite common to categorize an item (e.g. an adverb) in accordance with its prototypical function (e.g. as an adverbial), and then distinguish between 1) words capable of fulfilling this function by itself (e.g. 
a word like now) and 2a) lexically complex items, such as multi-word-units like at this point, and $2 \mathrm{~b}$ ) items functioning differently than prototypically expected (e.g. a noun like Sunday used adverbially as in Sunday, they came). This is a traditional form and function distinction.

Inasmuch as Danish grammars do mention interjections at all, they tend to treat the various interjections as lexical items, giving descriptions of the use of the items in question. Two works worth mentioning in this respect are published two hundred years apart. The first one is a grammar on Danish written by a teacher of arts and humanities at the Danish naval academy (Dichman 1800). The second one is the quite recent Grammatik over det Danske Sprog ("Grammar of the Danish Language") by Hansen \& Heltoft (2011). In both of these works, the difficulties in clear boundaries between the lexical categories are mentioned. So are the difficulties concerning the categorization of interjections. In both works, some general properties are treated, for instance the ability to form complete utterances by themselves, and also the difference between form and function, i.e. what many of the papers in this volume call the difference between primary and secondary interjections. However, the real interesting contributions of these works lie in the adjoining expositions whereby a selected number of interjections are treated one by one, with emphasis on their functional potential, i.e. their pragmatics. Thus, we are told that some interjections primarily serve as attention getters (in phatic communication), others serve as expressions of emotions and sensations, yet others serve as metalinguistic comments.

In written context, interjections have mostly been common in fiction or artistic writings. Especially in comics the interjections are numerous, and likewise the onomatopoetica; they belong to the specific features that draw the reader "into the thoughts and emotions of the protagonist" (Forster et al. 2012:133). In comics their written form is not fixed, but can show extensive variation and thereby convey both emotional and social meaning through orthographic choices (ibid:123). The orthographic variants of the interjections exhibit the same pattern as in general in social media and other non-formal and un-regulated writings, e.g. fanzines and graffiti (Androutsopoulos 2000, Sebba 2007): repetitions of letters (e.g. ahhh), choice of upper-case vs. lowercase letters (e.g. $\mathrm{OH}$ ), use of 'special' characters (e.g. whew!!), use of variant graphemes (e.g. whee or wee) and "paragraphematic variations", e.g. font, size, shape, color or orientation of the writing (Forster et al. 2012). Several drives are at stake here: economization (Androutsopoulos 2012, Hougaard 2013), prosodic spellings (Androutsopoulos 2000), language play (Danet 1995, Herring 1999) and the expressive (emotive) function (Jakobson 1960).

Due to the explosive growth of written online interaction (especially because of the social media) during the past 30 years (online chat interaction via IRC "Internet Relay Chat" has existed since the late 80's), linguistic and paralinguistic phenomena which were mostly associated with the spoken language, e.g. interjections, gestures and mimics, have gained ground in 
a new and 'customized' way. The situation of interactive writing to some extend corresponds to the situation of face to face-conversation, and this resemblance is often mentioned as an explanation of the prevalence of different representations of socio-emotional cues (Sproull \& Kiesler 1986). In an attempt to visually and verbally establish and support the understanding and relationship between sender and receiver in a written context, the interjections along with onomatopoetica, emoticons, emojis and other kinds of extralinguistic elements are employed. The appealing potency of the interjections along with their innate underdetermination is probably contributing to the increasing use of this unique word class. This supports the idea that visual and paralinguistic components in communication are vital, and the language in social media has re-actualized the study of interjections.

By revisiting interjections in Scandinavian Studies in Language, the explicit goal of the issue is to bring together Scandinavian and global perspectives on interjections. Ourvolume opens up Scandinavia-based research to the global audience, and at the same time, our analysis is characterized by deep connections with global scholarships in the plural. The seminal work on interjections by Wierzbicka (1991 [2003]); and Ameka (1992) had a crosslinguistic vision that continues to inspire the ongoing work of understanding both local interjections and global comparison. The early work by Wierzbicka and Ameka demonstrated that interjections are highly culturally-specific, but at the same time, that there are certain sub-classes, such as emotive (e.g. wow!), cognitive (e.g. aha!), volitive (e.g. psst!) interjection that seem to be universal. In contemporary diversity linguistics, lexico-semantic typology, and other new developments, there are several trends happening silmultaneously, such as big-scale comparisons, see e.g. Dingemanse, Torreria, and Enfield (2013), areal lexico-semantics, see e.g. Ponsonnet's work on interjections in Aborginal Australia (in press), and single-language-focused studies, such as Nordgren's recent monograph on Greek interjections.

Also, interjection studies seem to open up a wide array of interdisciplinary possibilities. Consider for instance, Goddard's work on interjection and emotion (2014), or Bromhead's historical work on era-specific interjections, and the link between interjections and societal change (2009). Such interdisciplinary advances continue to fuel the growing interest in the field. So do the rich discussions on how to capture in a precise definition what the somewhat slippery category of interjection means, and how it differs from related categories such as ideophones and discourse particles.

The multiple perspectives, the heterogeneity of approaches, and the emerging nature of the field, are underlined by many different kinds of contributions in this special issue.

Borchmann argues in favor of an ecological pragmatic approach to the analysis of interjections. With the point of departure in a traditional understanding of interjections being spontaneous and non-communicative, he shows that in addition to this basic function, interjections may also 
function as 1) non-spontaneous and communicative, and 2) spontaneous and communicative. Whereas the traditional understanding clearly shows an indexical sign relation, the latter two convey iconic and symbolic sign relations respectively.

Miltersen uses the Danish word $\varnothing v$ (used to convey vexation, disappointment and displeasure) as an occasion to question the criteria relied upon in lexical categorization. With the point of departure in traditional categorization of $\varnothing v$ as an interjection, it is shown 1) that the criteria are less consistent than usually thought, and 2) that the word $ø v$ in many cases exceeds the boundaries of what is considered interjections. The paper proposes a more pragmatically, functionally-based kind of categorization of lexical material.

In the field of Conversation Analysis and Interactional Linguistics, Steensig and Sørensen investigate the interactional functions of some of the most frequent interjections (particles) in Danish talk-in-interaction: ja ('yes'), $n e j$ ('no'), $m m$ ('mm'), nå (approximately 'oh'), and okay ('okay'). Their focus is the criteria for the choices interactants make when choosing one particle over another in "third position" after questions and answers, and they propose that a distinction between 'sufficient confirmation' particles and 'stance-oriented' particles can be made.

Several of the papers concern interjectionality in forms not ordinarily considered the primary locus of interjections (i.e. speech). The paper by Fabricius is one of these. Using a particular meme as case study, she shows how some properties usually associated with interjections may be borrowed by the meme, in particular the function of emotional outbursts and the ability to turn otherwise non-interjections into interjectional-like displays of emotion. The approach relies upon an understanding of interjections being gradable rather than belonging to discrete categories.

Another paper dealing with interjections in social media presents the study of the written interjections åh 'oh' and puha 'whew' in Facebook groups by Hougaard. This study takes a particular interest in existential and affective publics that arise on Facebook groups that deal with the diagnoses, treatment and terminal consequences of child cancer. The main argument is that the use of these exact interjections is a response to the affective and bodily experience of following the development of the child's illness as well as a signal about experiencing this affect. The interjections are bodily triggered affective expressions.

Levisen explores laughter interjections, i.e. expressive words of the type haha! The paper provides a new semantic and typological account of this sub-type of interjections that has not previously received much attention in the literature on interjections. From the vantage point of Danish, a language with an elaborate paradigm of laughter interjections, the paper develops an original analysis of interjectionalized laughter, and with special emphasis on two highly illuminating examples: hohøe and tøhø. 
Experts of spoken Israeli Hebrew Shor and Inbar contribute to interjection studies by an in-depth case study on zehu!, 'that's it.' Tracing the development from a demonstrative and pronominal element to a secondary interjection, the authors provide new evidence for two new meanings: the "zehu of completion" and the "zehu of restriction". The analysis engages with the international literature on interjections, and is backed up by corpus studies.

Mortensen studies interjection in courtroom interaction. Comparing the Danish and American courtroom, the linguistic footprints of two different cultural-institutional traditions known as "common law adversarialism" and "civil law inquisitorialism". Demonstrating the manifest differences in interactive style, the study provides new evidence for how micro-linguistic analysis can shed light on macro-societal question of justice, and how language, culture, and the law can intersect in different ways.

The final contribution by interjection specialist Stange, focusses on the discursive use of emotive interjections. With a case study on spoken British English, and a focus on social variables. The contribution sets new standards for the study of gendered interjection use. Based on corpus analysis, the paper provides an analysis of interjections such ow!, ouch!; ugh!, yuck!; whoops!, whoopsadaisy! Stange's study provides evidence for gender differences in the discursive use of emotive interjections, especially in young female speakers.

\section{References:}

Ameka, Felix. 1992. Interjections: The universal yet neglected part of speech. Journal of Pragmatics 18, 2-3, 101-118.

Androutsopoulos, Jannis. 2000. Non-standard spellings in media texts: The case of German fanzines. Journal of Sociolinguistics, 4(4), 514-533.

Androutsopoulos, Jannis. 2011. Language change and digital medie: A review of conceptions and evidence, ed. by Tore Kristiansen \& Nicholas Coupland. Standard Languages and Language Standards in a Changing Europe. Oslo. Novus, 145-159.

Bromhead, Helen. 2009. The Reign of Truth and Faith. Epistemic Expressions in 16th and 17th Century English. Berlin: Walter the Gruyter.

Dichman, Carl Fr. 1800. Forsøg til en dansk Sprogloere. Kiøbenhavn: Schultz.

Danet, Brenda (ed.). 1995. Play and performance in computer-mediated communication. JCMC 1(2). Available: http://209.130.1.169/jcmc/vol1/issue2/.

Dingemanse, Mark, Torreria, Francisco \& Enfield, N. J. 2013. Is "Huh?" a universal word? Conversational infrastructure and the convergent evolution of linguistic items. PLoS One 2013 Nov 8;8(11):e78273. doi: 10.1371/journal.pone.0078273.

Goddard, Cliff. 2014. Interjections and emotions, with special reference to "surprise" and "disgust". Emotion Review 6(1), 53-63.

Hansen, Erik \& Lars Heltoft. 2011. Grammatik over det danske sprog. København: Det Danske Sprog- og Litteraturselskab.

Herring, Susan H. 1999. Interactional Coherence in CMC. Journal of ComputerMediated Communication 4(4). 
Hougaard, Tina Thode. 2013. Hmmm...Interjektioner på Facebook, MUDS 14. Møde om Udforskningen af Dansk Sprog, ed. by Inger Schoonderbeek Hansen, Peter Widell \& Tina Thode Hougaard. Aarhus Universitet, 167-184.

Forster, Iris, Susanne R. Borgwaldt \& Martin Neef. 2012. Form follows function: Interjections and onomatopoetica in comics. Writing Systems Research 4(2), 122139, DOI: $10.1080 / 17586801.2012 .751348$

Jakobson, Roman. 1960. Closing Statement: Linguistics and Poetics. Style in Language, ed. by T. A. Sebeok. New York, London: The Technology Press of assachusetts Institute of Tecnology and John Wiley \& Sons, 350-377.

Nordgren, Lars. 2015. Greek Interjections: Syntax, semantics, and pragmatics. Berlin: De Gruyer Mouton.

Ponsonnet, Maïa. Submitted. Interjections. Oxford University Press Handbook of Australian languages, ed. by Claire Bowern. Oxford: Oxford University Press.

Sebba, Mark. 2007. Spelling and society: The culture and politics of orthography around the world. Cambridge, UK: Cambridge University Press.

Sproull, Lee \& Kiesler, Sara. 1986. Reducing Social Context Cues: Electronic Mail in Organizational Communications. Management Science 32(11), 1492-1512.

Wierzbicka, Anna. 2003 [1991]. Cross-Cultural Pragmatics: The semantics of human interaction. Berlin: Walter de Gruyter. 